\title{
Synergic Effects of Anticancer Peptide CIGB-552 and Cisplatin in Lung Cancer Models
}

\section{Yolanda Gomez Rodriguez}

University of Sherbrooke: Universite de Sherbrooke

\section{Brizaida Oliva Arguelles}

Center for Genetic Engineering and Biotechnology: Centro de Ingenieria Genetica y Biotecnologia https://orcid.org/0000-0003-4422-675X

Mario Riera Romo ( $\nabla$ rieraromo@gmail.com )

LUMC: Leids Universitair Medisch Centrum https://orcid.org/0000-0002-5384-5897

\section{Jorge Fernandez-De-Cossio}

Center for Genetic Engineering and Biotechnology: Centro de Ingenieria Genetica y Biotecnologia Hilda Elisa Garay Perez

Center for Genetic Engineering and Biotechnology: Centro de Ingenieria Genetica y Biotecnologia Julio Raul Fernandez Masso

Center for Genetic Engineering and Biotechnology: Centro de Ingenieria Genetica y Biotecnologia Maribel Guerra Vallespi

Center for Genetic Engineering and Biotechnology: Centro de Ingenieria Genetica y Biotecnologia

\section{Research Article}

Keywords: NSCLC, antitumor, synergism, combined therapy, CIGB-552, CDDP

Posted Date: July 21st, 2021

DOI: https://doi.org/10.21203/rs.3.rs-620068/v1

License: (c) (1) This work is licensed under a Creative Commons Attribution 4.0 International License. Read Full License

Version of Record: A version of this preprint was published at Molecular Biology Reports on January 30th, 2022. See the published version at https://doi.org/10.1007/s11033-022-07152-3. 


\section{Abstract}

Non-small cell lung cancer constitutes one the most frequent and lethal forms of the disease. The antitumor peptide CIGB-552 is a new targeted anticancer therapy which molecular mechanism is associated with the inhibition of the transcription factor NF-kB, mediated by COMMD1 protein stabilization. However, its pharmacological potential in combination with chemotherapy is unknown. In this study, we examined the antiproliferative capacity of CIGB-552 in combination with chemotherapeutic agents in the non-small cell lung cancer cell line $\mathrm{NCl}-\mathrm{H} 460$ and we confirmed drug interactions in vivo, in a mouse model of TC-1 lung cancer. We focus our research in the combination of CIGB-552 and the antineoplastic agent Cisplatin (CDDP) in a concomitant treatment. Our results demonstrate a clear synergic effect between $37.5 \mu \mathrm{M}$ of CIGB-552 and $5 \mu \mathrm{M}$ of CDDP under concomitant scheme, on proliferation inhibition, cell cycle arrest, apoptosis induction and oxidative stress response. The effect of CIGB-552 $(1 \mathrm{mg} / \mathrm{kg})$ and CDDP $(0.4 \mathrm{mg} / \mathrm{kg})$ administrated as a combined therapy was demonstrated in vivo in the TC-1 murine model where the combination achieved an effective antitumor response, without any deterioration signs or side effects. These findings demonstrate the efficacy of the concomitant combination of both drugs in preclinical studies and support the use of this therapy in clinical trials.

\section{Introduction}

Cancer represents one of the most challenging diseases in XXI century. Malignant transformation is a multistep process, where cancer cells gain properties like immune evasion, apoptosis resistance, insensitivity to antiproliferative signals, invasion, angiogenesis and metastasis. (Hanahan and Weinberg 2011). The website GLOBOCAN and the International Agency for Research on Cancer (IARC) estimated 18.1 million new cancer cases and 9.6 million cancer deaths in 2018. In both sexes combined, lung cancer is the most commonly diagnosed $(11.6 \%$ of the total cases) followed by female breast cancer and prostate cancer and is currently the leading cause of cancer death ( $18.4 \%$ of the total cancer deaths), closely followed in mortality by colorectal (9.2\%), stomach (8.2\%), and liver cancer (8.2\%). (Bray, Ferlay et al. 2018, 2020). In Cuba, cancer is the second cause of death (24\% of total deaths) just surpassed by heart and circulatory diseases (36,8\% of the total number of deaths) and lung cancer is still the one with more incidence and mortality among Cuban population. (2020).

Non-small cell lung cancer (NSCLC), represents the most frequent subtype of lung cancer with an $85 \%$ of incidence. The therapeutic strategies include surgery by early diagnostic, chemotherapy and radiotherapy in advanced cancer. The conventional chemotherapy protocols for NSCLC comprise 4 to 6 cycles of platinum-based doublet chemotherapy in first-line treatment and 6 cycles of docetaxel (or equivalent taxol drug) as a second-line regimen. Both regimens employ unspecific cytotoxic agents, which display numerous side effects (Wagner, Stollenwerk et al. 2020). The toxicity associated to chemotherapy affect the life quality of patients and nephrotoxicity, lymphopenia among other adverse reactions limit its longterm application in cancer therapy in addition to other negative impacts such as multidrug resistance (MDR), mutagenicity and teratogenicity (Bordoni 2008, Tiwari, Sodani et al. 2011). The combination of chemotherapy agents with other drugs that target specific tumor antigens or intracellular proteins such as 
monoclonal antibodies, peptides or small chemical inhibitors has demonstrated to be an efficient therapeutic strategy in NSCLC and other types of tumor (Li, Zhao et al. 2014, Achkar, Abdulrahman et al. 2018, Wagner, Stollenwerk et al. 2020) This attractive therapy achieves efficacy and decreases toxicity, reducing the doses of the antineoplastic agents without losing their effect. This can also contribute to attenuate MDR (Tallarida 2001, Bayat Mokhtari, Homayouni et al. 2017).

CIGB-552 is an antitumor peptide developed at the Center of Genetic Engineering and Biotechnology (CIGB), Havana, Cuba. Vallespi and her research group have demonstrated its cell penetrating capacity and proliferation inhibition of human and murine cancer cells in vitro (Fernández Massó, Oliva Argüelles et al. 2013, Astrada, Fernández Massó et al. 2018). Likewise, CIGB-552 elicits tumor regression in vivo, in syngeneic and xenograft mice models (Vallespí, Pimentel et al. 2014) as well as the stabilization of the disease and therapy improvement in pet dogs with spontaneous cancer (Vallespi, Rodriguez et al. 2017). The molecular studies of this peptide have shown inhibitory effects on NF-kB pathway through the stabilization and accumulation of the Copper Metabolism Mur 1 Domain Containing Protein 1 (COMMD1). This effect induces the ubiquitination and degradation of the NF-kB subunit RelA. In addition, CIGB-552 induces oxidative stress in tumor cells by the inhibition of the enzyme Superoxide-dismutase 1 (SOD1), causing lipid and protein peroxidation (Fernández Massó, Oliva Argüelles et al. 2013). These findings complemented by additional evidence in proteomic studies (de Villavicencio-Díaz, Gómez et al. 2015) suggest that the combination of CIGB-552 and conventional chemotherapeutic drugs such as Cisplatin (CDDP) or Paclitaxel could be attractive in preclinical and clinical settings. Therefore, in this work, we evaluated for the first time the combination of CIGB-552 with these antineoplastic agents widely use in lung cancer therapy, in the human NSCLC cell line NCI-H460. We explored two combination settings: pre-treatment and concomitant in order to select the optimal combination scenery to use in clinical trials, based on the estimation of the combination index (Cl) (Chou 2006). All the interactions were classified as synergistic, additive or antagonistic and their proliferation inhibition capacity was compared. The best combination was evaluated in terms of its effect on cell cycle progression, apoptosis induction and oxidative stress triggering. Furthermore, the potential benefit of the best combination and therapeutic scheme was corroborated in vivo in a mouse model of lung cancer.

\section{Materials And Methods}

\subsection{Reagents and Chemicals}

All regents and chemical substances used in this study were purchase from Sigma-Aldrich. Culture media and cell culture material were obtained from Life Technologies (USA), GE Healthcare, and Greiner. Fetal bovine serum (FBS) was acquired from HyClone, Logan, UT. All reagents for peptide synthesis were of synthesis grade. Reagents for chromatography were of high-performance liquid chromatography (HPLC) grade.

\subsection{Antineoplastic drugs}


The clinical grade chemotherapeutic drugs Cisplatin (CDDP), and Paclitaxel (Drug Research and Development Center, Havana, Cuba) were kindly provided by the Oncology Service of the National Institute of Oncology and Radiobiology (Havana, Cuba). Both were dissolved in buffered saline solution (PBS) for in vitro experiments and CDDP was also prepared in PBS for its administration in vivo.

\subsection{CIGB-552}

Peptide CIGB-552 was synthesized on a solid phase and purified by reverse-phase-HPLC to $>95 \%$ purity on an acetonitrile/ $\mathrm{H}_{2} \mathrm{O}$ trifuoracetic acid gradient and confirmed by ion-spray mass spectrometry (Micromass, Manchester, UK). The synthesis of the peptide in solid phase was performed using the Fmoc/t-Bu chemistry. The linking is direct to the $\mathrm{N}$-terminus of the peptide; there are no additional residues. Lyophilized peptide was reconstituted in phosphate buffered saline (PBS) for use in vitro and in vivo.

\subsection{Cell lines}

$\mathrm{NCl}-\mathrm{H} 460$ (human non-small cell lung carcinoma), MRC-5 cells (human embryonic lung fibroblasts) and TC-1 (murine lung epithelial cells transfected with VPH-16) were acquired from the ATCC and cultured in RPMI 1640 (for NCl-H460 and TC-1) and DMEM (for MRC-5), supplemented with Glutamax and 10\% (v/v) FBS according to the recommendations of the supplier. Cells were maintained in a $5 \% \mathrm{CO}_{2}$ atmosphere at $37^{\circ} \mathrm{C}$ in incubator. Cells were cultured for no longer than $10-15$ passages.

\subsection{Antiproliferative assays}

The effect of CIGB-552, CDDP and Paclitaxel on cell proliferation was then evaluated by a sulforhodamine B (SRB)-based assay according to the method described by the National Cancer Institute (Boyd 1997). NCl-H460 Cells were seeded at a density of $4 \times 10^{4}$ cells per well in a 96 -well plate (Costar, USA). Then after 24 hours they were incubated with the products $(10,40$ and $100 \mu \mathrm{M}$ of CIGB-552; 0.05, 5 and $50 \mu \mathrm{M}$ of CDDP and $0.2,20$ and $200 \mu \mathrm{M}$ of Paclitaxel) for 48 hours and the viability relative to untreated cells was measured by the SRB method. The percentage of cell proliferation inhibition was determined using CalcuSyn software (Version 2.1; Biosoft, Cambridge, UK). The assay was performed tree times with three replicas for each concentration.

\subsection{In vitro drug combination study}

The drug combination study was carried out in 96-well plates seeded with $\mathrm{NCl}-\mathrm{H} 460$ cells $\left(4 \times 10^{4}\right.$ cells per well) and the cell viability was measured after 48 hours of treatment using the (SRB)-based assay as we described above. Cells were treated with different concentrations of CIGB-552 (300-9.37 $\mu \mathrm{M})$ and the antineoplastic drugs (500-5 $\times 10^{-3} \mu \mathrm{M}$ of CDDP or $2-2 \times 10^{-4} \mu \mathrm{M}$ of Paclitaxel) according to a Latin square design (Chou 2006). The assay was performed under two different treatment schemes: concomitant (CIGB-552 and the chemotherapeutic agent were added at the same time) and pre-treatment (cells were pre-incubated with CIGB- 552 for 5 hours, then it was eliminated from culture media and the cytostatic drug was added). The effect on cell proliferation was determined relative to untreated cells in two independent experiments. The results were analyzed with CalcuSyn software to determine the type of 
interaction (synergism, additivity or antagonism), according to the obtained combination index (Cl) values. The software also calculated the dose reduction index (DRI) and the fraction affected (Fa) which is related with the magnitude of effect for each combination. The 2D interaction maps with color-coded surfaces were created using Matlab® R2012a software based on the $\mathrm{Cl}$ and Fa values.

\subsection{Cell cycle analysis}

The cell cultures were incubated with CIGB-552 $(37.5 \mu \mathrm{M}), \operatorname{CDDP}(5 \mu \mathrm{M})$ and their combination for 12 and 24 hours. Subsequently, the cells were collected by trypsinization, washed and fixed with ice-cold methanol/acetone (4:1) at $4^{\circ} \mathrm{C}$ for 1 hour. Cells were then stained by incubation for 20 min at $37^{\circ} \mathrm{C}$ with a solution of $100 \mathrm{mg} / \mathrm{ml} \mathrm{PI}$ and $10 \mathrm{mg} / \mathrm{ml}$ of DNase-free RNase. Stained cells were analyzed on a Becton Dickinson FACSCalibur cytometer using the cell cycle analyzer from CellQuest software. Prior to fitting the DNA distribution to a diploid DNA content for cell cycle profiling, cellular debris and doublets were properly excluded by gating out in FL3-A vs. FL3-W two-parameter dot plots.

\subsection{Western Blot of apoptosis related proteins}

$\mathrm{NCl}-\mathrm{H} 460$ cells were treated with CIGB-552 $(37.5 \mu \mathrm{M}), \mathrm{CDDP}(5 \mu \mathrm{M})$ and both drugs combined, as well as $1 \mu \mathrm{M}$ of Staurosporin (STS) as positive control. Cell fractioning was performed as described previously (Thoms, Loveridge et al. 2010) using Lysis Buffer (Cell Signaling, USA) and protein inhibitor cocktail (Roche, USA), according to the instructions of the supplier. Proteins in whole cell extracts $(30 \mu \mathrm{g})$ were resolved by electrophoresis on $12.5 \%$ and $15 \%$ polyacrylamide gels (Bio-Rad technology, USA) and analyzed according to the western blotting technique previously described (Burnette 1981). Briefly, the proteins were transferred to a nitrocellulose membrane (pore size $0.45 \mathrm{~mm}$ ) and incubated with the appropriate primary antibody (1:500-1:1000 dilution). After incubation with peroxidase-conjugated secondary antibody (1:2000), protein specific bands were visualized using chemiluminescence reagents followed by exposure to standard X-ray films.

\subsection{Annexin V/ Propidium iodide double staining}

Cells in early and late stages of apoptosis were detected with an Annexin V-FITC apoptosis detection kit from Sigma (041M4083). NCl-H460 cells ( $1 \times 10^{5}$ cells per well) were treated with CIGB-552 (37.5 $\left.\mu \mathrm{M}\right)$, $\operatorname{CDDP}(5 \mu \mathrm{M})$ or the combination in 12-well plates (Costar, USA) and incubated for 48 hours prior to analysis. STS $(1 \mu \mathrm{M})$ was used as positive control of apoptosis induction. Then, cells were trysinazed, collected and resuspended in $1 \mathrm{x}$ binding buffer. To $100 \mu \mathrm{L}$ of cell suspension, $5 \mu \mathrm{L}$ of Annexin V-FITC and $10 \mu \mathrm{L}$ propidium iodide $(\mathrm{PI})$ were added and incubated for $10 \mathrm{~min}$ at room temperature prior to analysis. Samples were analyzed (20,000 events) using the Becton Dickinson FACSCalibur instrument and CellQuest software. Cells that were positive for Annexin V-FITC alone (early apoptosis) and Annexin VFITC and PI (late apoptosis) were counted.

\subsection{Superoxide anion accumulation assays}

The detection of superoxide anion formation as a measure of oxidative stress induction was determined as previously described (Wojtala, Bonora et al. 2014). NCl-H460 and MRC-5 cells were seeded at a density 
of $6 \times 10^{3}$ and $1 \times 10^{4}$ cells per well, respectively, in 96 -well plates. After 24 hours they were treated with CIGB-552 $(37.5 \mu \mathrm{M}), \mathrm{CDDP}(5 \mu \mathrm{M})$ and the combination for 1 hour. Hydrogen peroxide $\left(\mathrm{H}_{2} \mathrm{O}_{2}\right) 2.5 \mu \mathrm{M}$ was used as positive control. Then cells were incubated with $10 \mu \mathrm{M}$ of Hydroethidine (HE) for 1 hour to visualize the superoxide anion formation. The fluorescence was detected and measured using confocal microscopy (Inverted microscope Olympus, Japan). The images acquired were analyzed with the software ImageJ 1.41 to quantify the fluorescence intensity as fold of control for all treatments. We processed images from three independent experiments.

To confirm the induction of oxidative stress in NCl-H460 cells, we perform a flow cytometry-based assay for HE detection in treated cells according to the method described by Walrand and colleagues (Walrand, Valeix et al. 2003). Briefly, we seeded $1 \times 10^{6}$ cells per well and treated with the products alone and combined for 12 hours. Untreated cells and cells incubated with $2.5 \mu \mathrm{M}$ of Hydrogen peroxide $\left(\mathrm{H}_{2} \mathrm{O}_{2}\right)$ for 12 hours were the negative and positive control, respectively. Cells were mechanically detached in cold and cell suspensions were obtained by centrifugation at $300 \mathrm{xg}$ for 5 minutes at room temperature. Pellets were re-suspended in PBS $1 \mathrm{X}$ and incubated with HE $(10 \mu \mathrm{M})$ for 30 minutes at $37^{\circ} \mathrm{C}$ protected from light. Then cells were analyzed in the Becton Dickinson FACSCalibur cytometer and corresponding CellQuest software. A total of $2 \times 10^{4}$ events were analyzed and HE positive cells were quantified. We established forward and side scatter gates from negative control cells to exclude debris and cellular aggregates.

\subsection{In vivo drug interaction experiments}

C57/BL6 female mice of 8 weeks old and 18-20 g (a total of 40 animals) were randomly divided into 4 groups of 10 animals each. Mice were injected with $5 \times 10^{4}$ cells per animal of the murine tumor cell line TC-1 on the right flank, according to the procedures reported for this animal model (Tanaka, Delong et al. 2005). When tumors reached $70-90 \mathrm{~mm}^{3}$ we start the administration of the products at the indicated doses. Group 1 received saline solution (PBS 1x) by subcutaneous route three times a week during three weeks (control group). Group 2 was subcutaneously administered with $1 \mathrm{mg} / \mathrm{kg}$ of CIGB-552, three times a week during three weeks. Group 3 received $0.4 \mathrm{mg} / \mathrm{kg}$ of CDDP by intraperitoneal route three times a week only during the first week of administration. Group 4 was administered with a combination of both drugs: CIGB-552 (1 mg/kg) subcutaneously three times a week during three weeks and CDDP $(0.4 \mathrm{mg} / \mathrm{kg})$ intraperitoneally three times a week during the first week. Animals were weighted once a week since the beginning of the experiment. Tumors were measured three times a week with a caliper and their volumes were calculated according to the following formula: volume = length $\mathrm{x}$ width ${ }^{2} / 2$. Survival rate was daily registered during the experiment and only when tumor volumes reached $2,000 \mathrm{~mm}^{3}$, the animals were sacrificed due to ethical considerations. Mice were maintained under pathogen-free conditions and all the procedures were performed in accordance with the recommendations for the proper use and care of laboratory animals at the Center for Genetic Engineering and Biotechnology (Havana, Cuba). This animal study complies with all the international requirements and is according the National Institutes of Health guide for care and use of laboratory animals. 


\subsection{Statistical analysis}

The drug-drug interactions were determined and validated using the software CalcuSyn version 2.0, (1997, Biosoft, EUA). The percentages of cell proliferation inhibition, AV + AV/PI positive cells, HE fluorescence intensity (fold of control) and number of affected animals from in vivo experiments were compared between the combination and the individual treatments using one way ANOVA and Dunnet post test. The number of HE positive cells in percent determined using flow cytometry, as well as tumor

volumes from in vivo experiments were compared between the combination and the individual treatments by unpaired $T$ tests. The statistical significance of differences in survival rates was determined by logrank test $p^{*}<0,05$. All statistical analysis were done using the software GraphPad Prism 7.

\section{Results}

\subsection{CIGB-552 and cytostatic drugs are synergic in human lung cancer cells}

First, we evaluated and compared the cytotoxicity of our anticancer peptide CIGB-552 in combination with cytostatic drugs commonly used in chemotherapy of lung cancer, such as CDDP and Paclitaxel, in the human lung cancer cell line $\mathrm{NCl}-\mathrm{H} 460$. We selected this cell line based on previous results obtained in our lab that reveal a major cytotoxic potential in $\mathrm{NCl}-\mathrm{H} 460$ cells in comparison to other human lung cancer cell lines (data not shown). In addition, the molecular mechanism of CIGB-552 has been fully characterized by us in NCl-H460 cells (Fernandez J et al., 2013). We have previously obtained and corroborated the cytotoxic effect of CIGB-552, CDDP and Paclitaxel in this cell line, with $\mathrm{IC}_{50}$ values of 44.6, 1.99 and $0.01 \mu \mathrm{M}$, respectively (data not shown). Based on these evidences we decided to evaluate the antiproliferative capacity of the peptide and both cytostatic drugs separately and combined in $\mathrm{NCl}-$ $\mathrm{H} 460$ cells, testing different concentrations below and above the $\mathrm{IC}_{50}$ as it is recommended. All treatments were able to inhibit cell proliferation in a concentration dependent manner, but this effect was more potent combining the peptide with the cytostatic drugs, particularly at lower concentrations where the effects of both products is not overlapped (Fig. 1A and B). To corroborate this possible synergic effect and to identify other pharmacological interactions, the antiproliferative capacity of CIGB-552 combined with CDDP and Paclitaxel in a wider range of concentrations was evaluated in the lung cancer cell line $\mathrm{NCl}-\mathrm{H} 460$, by an in vitro drug combination assay. We treated the cells with CIGB-552 and both cytostatic drugs alone and in combination, using two different settings: concomitant and pre-treatment. The results were analyzed with the software Calcusyn to determine the significance or grade of combination (synergism, additivity and antagonism) based on two main parameters: combination index (Cl) and dose reduction index (DRI) (Table 1). 
Table 1

Combination parameters under concomitant treatment for maximal, minimal and median concentrations of CIGB-552, CDDP and Paclitaxel in NCl-H460 cells.

\begin{tabular}{|lllllllll|}
\hline CIGB-522 $(\mu \mathrm{M})$ & CDDP $(\mu \mathrm{M})$ & $\mathbf{F a}$ & $\mathbf{C l}$ & DRI & Paclitaxel $(\mu \mathrm{M})$ & $\mathrm{Fa}$ & $\mathbf{C l}$ & $\mathrm{DRI}$ \\
\hline $\mathbf{3 0 0}$ & $\mathbf{5 0 0}$ & 0.9 & 4 & 1.2 & $\mathbf{2}$ & 0.9 & 4.5 & 0.3 \\
\hline $\mathbf{3 7 . 5}$ & $\mathbf{5}$ & 0.8 & 0.3 & 11.4 & $\mathbf{0 . 2}$ & 0.9 & 0.7 & 1.3 \\
\hline $\mathbf{9 . 3 7}$ & $\mathbf{0 . 0 0 5}$ & 0.9 & 0.8 & 7.5 & $\mathbf{0 . 0 0 0 0 2}$ & 0.6 & 0.9 & 13.7 \\
\hline \multicolumn{7}{l}{ Cl, combination index; Fa, fraction affected; DRI, dose reduction index. } \\
\hline
\end{tabular}

In the concomitant setting, we observed antagonism between $300 \mu \mathrm{M}$ of CDDP and $150 \mu \mathrm{M}$ of CIGB-552; however, this concentration of the peptide interacted with $50 \mu \mathrm{M}$ of CDDP, producing an additive effect with $95 \%$ of cell proliferation inhibition. Interestingly, the synergism was observed in concentrations below $150 \mu \mathrm{M}$ of CIGB-552 and $50 \mu \mathrm{M}$ of CDDP where the cell growth inhibition is still $95 \%$ in the range of 37.5 $\mu \mathrm{M}$ to $9.37 \mu \mathrm{M}$ of CIGB-552. The synergism is potent in $0.5-5 \mu \mathrm{M}$ of CDDP and 18.75-9.37 $\mu \mathrm{M}$ of CIGB552, with $\mathrm{Cl}$ values between 0.7 and 0.1 (Fig. 1C). Compared with the concomitant, pre-treatment analysis showed antagonic effect in maximal and minimal concentrations of both drugs, being potent in two zones: $500 \mu \mathrm{M}$ of CDDP with the full concentration range of CIGB-552 and also $0.5-5 \mu \mathrm{M}$ of CDDP with 18.75-9.37 $\mu \mathrm{M}$ of CIGB-552, demonstrating that the surface of synergism is reduced under this treatment scheme. Therefore, the concomitant scenario is better to combine these drugs in $\mathrm{NCl}-\mathrm{H} 460$ cells.

The combination of CIGB-552 with Paclitaxel showed a different behavior. In concomitant scheme we observed additivity between various concentrations of Paclitaxel and $150-75 \mu \mathrm{M}$ of CIGB-552. On the other hand, the synergic effect was found in concentrations lower than $75 \mu \mathrm{M}$ of CIGB-552 and $0.2 \mu \mathrm{M}$ of Paclitaxel, with $90 \%$ of cell proliferation inhibition. Specifically, the range $0.002-0.0237 \mu \mathrm{M}$ of Paclitaxel with the full range of CIGB-552 achieves a potent synergism $(\mathrm{Cl}=0.3-0.1)$ with $85 \%$ of cell death. As occurs with de combination of CIGB-552 and CDDP, the pre-treatment setting reduced the synergism surface to the area of $0.002-0.02 \mu \mathrm{M}$ of Paclitaxel with concentrations of CIGB-552 under $150 \mu \mathrm{M}$ (Fig. 1C). In addition, the effect on cell growth inhibition was minor in comparison to the concomitant design.

These results show a clear synergic effect for the peptide with both chemotherapeutic drugs demonstrating a major surface of synergism under the concomitant combination respect to pre-treatment condition. Another aim of this analysis is to predict a reduction of toxicity using the DRI value, especially for drugs such as cytostatics due to their adverse effect during cancer treatment. The DRI of CDDP and Paclitaxel in combination with CIGB-552 is attractive and could be beneficial for chemotherapy, particularly at low concentrations (DRI > 1) (Table 1). According to this data, by using CIGB-552 as adjuvant treatment the doses of CDDP could be reduced from 7 to 11 times in a combined therapy maintaining a proliferation inhibition around $80-90 \%$, whereas Paclitaxel doses could be reduced up to 13 times, but achieving a $60 \%$ of proliferation inhibition. As is suggested by these results, the 
combinations studied could help to reduce the doses of CDDP and Paclitaxel currently used in the clinical practice, keeping the efficacy and synergism observed.

From these experimental data we also conclude that CIGB-552 combined with CDDP exhibits a higher synergism index and a greater cell growth inhibition compared to Paclitaxel in several concentrations evaluated. Also, the synergism observed was better in surface and inhibition under concomitant treatment. For those reasons, we selected the combination of CIGB-552 and CDDP in concomitant scheme to continue the study. Interestingly, the major inhibition of cell growth and the higher synergism were obtained at concentrations below the $\mathrm{IC}_{50}$ of CIGB-552 $(37.5 \mu \mathrm{M})$ and above the $\mathrm{IC}_{50}$ of CDDP (5 $\mu \mathrm{M})$. According to this, we decided to evaluate the effect of both drugs on subsequent experiments at these particular concentrations.

\subsection{The combination of CIGB-552 and CDDP affects cell cycle progression}

CIGB-552 and CDDP inhibited the proliferation of $\mathrm{NCl}-\mathrm{H} 460$ cells and both products combined reached a higher effect compared with their individual inhibition. According to this, we evaluate their capacity to interfere with cell cycle progression in $\mathrm{NCl}-\mathrm{H} 460$ cells at 12 and 24 hours of exposure, assessing the DNA content and the cell cycle phases with Propidium lodide (PI) measured by flow cytometry. CIGB-552, CDDP and their combination affected cell cycle progression of $\mathrm{NCl}-\mathrm{H} 460$ cells in a time dependent manner (Fig. 2). CIGB-552 induced cell cycle arrest at G2/M phase (20.95\%) from 12 hours of treatment compared to control (untreated cells) and this effect was maintained after 24 hours of exposure (20.76\%). On the other hand, CDDP strongly modified the cell cycle profile of $\mathrm{NCl}-\mathrm{H} 460$ cells, inducing cell death (2.58\% at 12 hours and up to $10.57 \%$ at 24 hours) and causing a clear cell cycle arrest at G2/M phase $(47.82 \%$ and $53.40 \%$ at 12 and 24 hours, respectively). Interestingly, both drugs together induced a mixed cell cycle profile which results from the combination of their individual effects causing G2/M arrest ( $19.67 \%$ in 12 hours and $21.12 \%$ at 24 hours) and potentiating cell death, particularly at $12 \mathrm{~h}$ of incubation (Fig. 2A).

\subsection{CIGB-552/CDDP combination activates the apoptotic pathway}

The combination of CIGB-552 and CDDP showed an increased capacity to inhibit the proliferation of $\mathrm{NCl}-$ $\mathrm{H} 460$ cells promoting cell death and causing perturbations in cell cycle progression, so we decided to explore the ability of both products combined to induce apoptosis in this cell line. For this purpose, we evaluated the effect of CIGB-552 and CDDP separately and combined on the activation of the apoptotic pathway. First, in order of explore at a molecular level the effect of the combination on apoptosis-related proteins we performed a western blot analysis in $\mathrm{NCl}-\mathrm{H} 460$ cells, to study whether the cell death observed is related to the activation of Caspase 3 (effector) and Caspase 8 and 9 (initiators), as well as the cleavage of PARP, a well-known apoptosis marker. We treated the cells with CIGB-552, CDDP and the combination of both for 12 and 24 hours. We used $1 \mu \mathrm{M}$ of Staurosporin (STS) as positive control. In Fig. $3 \mathrm{~A}$, we show how the Pro-Caspase 3 decreases in the combination treatment after 24 hours of exposure 
respect to CIGB-552 and CDDP, indicating the formation of active Caspase 3. At 12 hours, the cleavage of Caspase 8 was observed in STS treatment solely, but after 24 hours, we detected the active form of Caspase $8(41 / 43 \mathrm{kDa})$ in all conditions evaluated, with a major accumulation in the combined treatment. In the case of Caspase 9 , the band corresponding to the active form $(37 / 35 \mathrm{kDa})$ was detected at 12 hours, and this band was more intense in the combination. However, after 24 hours of exposure we found no differences in the cleavage of this protein between CDDP and the combination. Regarding the cleavage of PARP protein as a general marker of apoptosis it was observed since 12 to 24 hours of exposure in all treatments and the band is particularly strong after 12 hours of incubation with CIGB552/CDDP combination. Interestingly, after 24 hours of treatment with the combination, the cleavage of PARP was extensive and similar to STS. These results indicate the activation of Caspases 3,8 and 9 as well as the cleavage of PARP by the combination of CIGB-552 and CDDP, demonstrating the stimulation of the apoptotic pathway.

Next, we decided to confirm apoptosis induction in $\mathrm{NCl}-\mathrm{H} 460$ cells by the Annexin V/Propidium iodide (AV/PI) double staining, evaluated by flow cytometry. Cancer cells were incubated with CIGB-552 and CDDP in monotherapy and combination during 48 hours. We also used STS $(1 \mu \mathrm{M})$ as positive control. All treatments increased the population of cells stained with AV (early apoptosis) and AV/PI (late apoptosis) respect to non-treated cells. In particular, the detection of AV/PI positive cells was higher for the combined treatment in comparison to CIGB-552 and CDDP alone (Fig. 3B). We graphed the percentage of AV + AV/PI positive cells for a better understanding. The effect of the combination reaches a $62.7 \%$ of stained cells respect to $20.4 \%$ and $34.5 \%$ with CIGB-552 and CDDP, respectively (Fig. 3C).

Altogether, these results demonstrate that the combination of CIGB-552 and CDDP have a negative effect on the survival of $\mathrm{NCl}-\mathrm{H} 460$ lung cancer cells inducing apoptosis as the mechanism of cell death. The effects exerted by the combination are more potent compared to the drugs alone confirming the synergic interaction between them.

\subsection{Synergic antitumor effect of CIGB-552/CDDP combination is mediated by Oxidative Stress activation}

The molecular mechanism of CIGB-552 peptide in lung cancer cells is related with the induction of oxidative stress. CDDP in addition to its DNA intercalating activity also promotes the formation of Reactive Oxygen Species (ROS) and oxidative damage in tumor cells. For that reason, we expected a connection between the antitumor mechanism of the combination and the cell redox balance. According to this, we evaluated the formation of superoxide radical (02--) in $\mathrm{NCl}-\mathrm{H} 460$ cells after exposure to the products in study. Cells were incubated with CIGB-552, CDDP and the combination during 1 hour and then they were stained with Hydroethidine (HE) to visualize the formation of superoxide anion. A 1 hour exposure to $2.5 \mu \mathrm{M}$ of hydrogen peroxide $\left(\mathrm{H}_{2} \mathrm{O}_{2}\right)$ was used as positive control for the experiment. Both, the treatment with CIGB-552 and the combination promoted the increase of fluorescence in treated cells, demonstrating the accumulation of $02 \cdot-$, in contrast to CDDP that showed a minor effect (Fig. 4A). Comparing the mean fluorescence intensity of $\mathrm{HE}$ for the different treatments we can observe that CIGB- 
552 produced a 1.8 fold increase in comparison to control (untreated cells) and combined with CDDP the fold increase is up to 2.8 , which is statistically different from their individual effects (Fig. 4B). To evaluate the selectivity of ROS induction as antitumor mechanism we tested the same concentrations of CDDP and CIGB-552 alone and combined during 1 hour of exposure in human lung fibroblasts (MRC-5 cell line). As we expected the evaluated products do not stimulate 02-- accumulation in these cells (Fig. 4C), suggesting that CIGB-552 and the combination induce this mechanism selectively in tumor cells in comparison to non-transformed cells from the same histologic localization. Then, in order to corroborate the ROS production in $\mathrm{NCl}-\mathrm{H} 460$ cells in response to our products and to verify this effect after a prolonged exposure, we determined the percentage of $\mathrm{HE}$ positive cells after 12 hours of incubation with CIGB-552, CDDP and the combination of both, using flow cytometry. We used $\mathrm{H}_{2} \mathrm{O}_{2}(2.5 \mu \mathrm{M})$ as positive control. The accumulation of $02 \cdot-$ was detected after 12 hours of incubation in cells treated with CIGB552 ( $5 \%$ of positive cells) and interestingly in CDDP-treated cells in a similar extent (5.3\% of positive cells). Comparing this effect with the HE fluorescence obtained after 1 hour of exposure, we confirm our hypothesis that CIGB-552 induces oxidative stress as an early event that is maintained, whereas CDDP activates ROS later in time; but in both cases this mechanism leads to apoptosis induction and cell death. In line with this, the combined treatment showed a significant increase in the percentage of HE positive cells $(13.8 \%)$, demonstrating synergy in the induction of oxidative stress mediated by the products (Fig. 4D).

There is an increase on superoxide radicals when cells are treated with CIGB-552 and this effect is stronger in combination with CDDP, as occurs with the other parameters included in our study. In addition, not CIGB-552 or the combination promote the generation of superoxide anion in normal cells. Thus, the combination could help to decrease the non-specific toxicity promoted by Cisplatin, keeping the increase of ROS as a selective mechanism of cytotoxicity in tumor cells.

\subsection{CIGB-552 and CDDP are synergic in vivo in a mouse model of lung cancer}

The combination of CIGB-552 and CDDP has shown synergistic effect in $\mathrm{NCl}-\mathrm{H} 460$ cells inducing apoptosis and oxidative stress. However, the in vivo antitumor efficacy of both drugs combined in lung cancer animal models is still unknown. We have previously established the pharmacokinetic profile of CIGB-552 in BALB/c mice and validated its antitumor activity in syngeneic and xenograft mouse models of colon cancer (Vallespí, Pimentel et al. 2014). Subcutaneous administration of 0.72 or $1.44 \mathrm{mg} / \mathrm{kg}$ of CIGB-552 was able to inhibit tumor growth and improve survival rate without toxicity signs or body weight loss in comparison to a reference drug such as Oxaliplatin. In line with these previous results, we decided to explore the effects of the systemic administration of CIGB-552 and CDDP alone and as a combined therapy in a syngeneic mouse model of TC-1 lung cancer. First, we analyzed the antiproliferative capacity, in vitro drug interactions and the oxidative stress induction promoted by CIGB-552 and CDDP in the mouse tumor cell line TC-1 (murine lung epithelial cells transfected with VPH-16) under the same conditions of $\mathrm{NCl}-\mathrm{H} 460$ cells. In this murine cell line, CIGB-552, CDDP and the combination inhibited cell proliferation, displaying synergism in a similar concentration range compared to $\mathrm{NCl}-\mathrm{H} 460$ cells and

Page $11 / 27$ 
increasing the accumulation of superoxide radicals (Supplementary Fig. 1S). Then we generated the syngeneic mouse model of lung cancer by subcutaneous implantation of TC-1 cells in C57/BL6 mice, to evaluate the antitumor activity of CIGB-552/CDDP combination in vivo. We based on our previous results of CIGB-552 pharmacokinetics and antitumor efficacy in colon cancer models to select the dose and administration route, following the experimental design described in materials and methods (Sect. 2).

The administration of CIGB-552 and CDDP on tumor-bearing mice led to a significant reduction of tumor growth compared with the group treated with saline solution $(p<0,05)$ (Fig. 5A and B). In addition, mice treated with the combination exhibited significantly less tumor volume than those only administered with CIGB-552 or CDDP $(p<0,05)$. The treatment was also safe and tolerable for mice included in the study, as we could corroborate by monitoring the body weight and possible toxicity signs of treated animals. CIGB552 and the combination practically did not affect the life quality, whereas animals administered with CDDP or saline solution (control group) presented obvious signs of physical deterioration such as piloerection, ulcers, fallen hind legs and bending. All treatments in general were tolerable maintaining a constant increase in body weight during the whole experiment (Fig. 5C). However, the peptide and the combined treatment significantly decreased the presence of physical deterioration signs and the percentage of affected animals in comparison to CDDP administration (Table 2).

Table 2

Signs of physical deterioration 36 days post-implantation in the syngeneic mouse model of TC-1 lung cancer treated with CIGB-552, CDDP and combined therapy.

\begin{tabular}{|c|c|c|c|c|c|}
\hline \multirow[t]{2}{*}{ Experimental Groups $(n=10)$} & \multicolumn{4}{|c|}{$\begin{array}{l}\text { Physical deterioration after } 36 \text { days post- } \\
\text { implantation } \\
\text { (Number of affected animals) }^{a}\end{array}$} & \multirow[t]{2}{*}{$\begin{array}{l}\text { Incidence } \\
(\%)^{b}\end{array}$} \\
\hline & Piloerection & Ulcers & $\begin{array}{l}\text { Fallen hind } \\
\text { legs }\end{array}$ & Bending & \\
\hline PBS 1X & $2 / 10$ & $3 / 10$ & $1 / 10$ & $3 / 10$ & 40 \\
\hline CIGB-552 (1 mg/kg) & $1 / 10$ & - & - & - & 10 * \\
\hline CDDP (0.4 mg/kg) & $1 / 10$ & $4 / 10$ & $2 / 10$ & $1 / 10$ & 50 \\
\hline $\begin{array}{l}\text { CIGB-552 }(1 \mathrm{mg} / \mathrm{kg})+\text { CDDP }(0.4 \\
\mathrm{mg} / \mathrm{kg})\end{array}$ & - & - & - & - & 0 * \\
\hline
\end{tabular}

a Number of animals with each symptom/total) ; ${ }^{b}$ Number of animals with one or more symptoms/ total (in \%); $p<0.05$ compared to the CDDP treated group (One way Anova and Dunnet post test)

In line with the reduction observed for tumor volume in this model and the absence of physical deterioration signs, mice treated with the peptide CIGB-552 and the combination improved life quality and increased survival rate respect to CDDP or saline solution groups. The survival rate for all treatments was significantly different compared to PBS administration $(p<0,01)$ and the combination shows a tendency to a superior overall survival in comparison to individual treatments, marked by the fact that only the combined treatment group still have live animals at the end of the experiment (Fig. 5D). The treatment 
with the combination was very effective in comparison to monotherapies, with a treated/control ratio (T/C) less than 15 (1.9), a tumor growth delay (TGD) of 9.5 days respect to control group and achieving a $98 \%$ of tumor growth inhibition (Table 3 ). Thus, our results demonstrate that CIGB-552/CDDP combination scheme elicits its antitumor activity in vivo, with high tolerability and effectiveness.

Table 3

Effectiveness of the combination therapy in the syngeneic mouse model of TC-1 lung cancer

\begin{tabular}{|c|c|c|c|}
\hline Treatment & TGI (\%) & $\mathrm{T} / \mathrm{C}$ & TGD (days) \\
\hline CIGB-552 (1 mg/kg) s.c & 60.7 & 39.3 & 6.5 \\
\hline CDDP $(0.4 \mathrm{mg} / \mathrm{kg})$ i.p & 86.7 & 13.3 & 5.8 \\
\hline CIGB-552 (1 mg/kg) s.c + CDDP (0.4 mg/Kg) i.p & 98.1 & 1.9 & 9.5 \\
\hline \multicolumn{4}{|c|}{$\begin{array}{l}\text { TGI, tumor growth inhibition; TGD, tumor growth delay; } T / C \text {, treated and control animals ratio ( } 15 \\
\text { highly effective, }<50 \text { effective, } 15-50 \text { moderate, }>50 \text { no effective); s.c, subcutaneous route; i.p, } \\
\text { intraperitoneal route. }\end{array}$} \\
\hline
\end{tabular}

\section{Discussion}

The generation of new therapeutic strategies and alternative treatments has been a focus on cancer research. Drug combination in particular, is getting attention as an interesting approach with a great current impact in cancer therapy. The idea is to achieve a synergic or additive effect between the drugs in the combination, in order to potentiate their individual properties, reducing the doses but maintaining the pharmacological effect, which allows the reduction of tumour growth and metastatic potential, decreasing stem cell populations and inducing apoptosis, and at the same time reducing toxicity and MDR (Tallarida 2001, Li, Zhao et al. 2014, Bayat Mokhtari, Homayouni et al. 2017, Achkar, Abdulrahman et al. 2018).

In this work, we evaluated the pharmacological effects of the combination between our anticancer peptide CIGB-552 and classic antineoplastic agents currently employed in the clinics for lung cancer treatment, such as CDDP and Paclitaxel. We evaluated potential pharmacological interactions between CIGB-552 and both CDDP and Paclitaxel through an in vitro drug combination assay in the NSCLC cell line $\mathrm{NCl}-\mathrm{H} 460$. We used two different combination schemes: concomitant (both drugs acting at the same time) and pre-treatment (preincubation with CIGB-552 and then add the other drug) similar to clinical schemes used for cancer patients.

This drug interaction study showed a clear synergic effect between CIGB-552 and both chemotherapeutic agents but the synergism and the antiproliferative capacity were higher with CDDP compared to Paclitaxel under the two treatment settings, and particularly under concomitant conditions, where the synergism surface and the fraction affected were greater. This indicate that co-administration of both drugs is essential to obtain a better synergistic effect and a greater inhibition of cell proliferation in nonsmall cell lung cancer lines. This study also revealed some additivity between CIGB-552 and CDDP at 
middle concentrations, which could potentiate their overall effect, although synergism was the predominant interaction observed. Antagonism was only present at higher concentrations in the concomitant condition, suggesting that these drugs combined are more effective at middle and lower concentrations. According to this, CDDP/CIGB-552 combination also showed a best DRI at the lower concentrations, what also suggest that CIGB-552 could help to reduce the doses of CDDP currently used in the clinic, improving the patient responses to this antineoplastic agent. Based on this result, we selected the combination of CIGB-552 and CDDP, under concomitant scheme, to further evaluate its antitumor properties and the synergism between both drugs.

Next, we investigated the capacity of the combination to modulate cell cycle progression and induce apoptosis in $\mathrm{NCl}-\mathrm{H} 460$ cells. Our results demonstrated cell cycle arrest at G2/M phase and DNA fragmentation which is an indicative of cell death. On the other hand, we confirmed apoptosis induction in $\mathrm{NCl}-\mathrm{H} 460$ cells in response to our products, which was increased by the combination. Cell death by apoptosis is one of the most important mechanisms that intrinsically controls malignant transformation. Thus, apoptosis induction in tumor cells is considered a key indicator of antitumor activity for new products/drugs and is also a desirable effect for drug combinations (Meng, Wang et al. 2015). It has been described that some chemotherapeutic agents such as CDDP, Topotecan and Gemcitabine are able to induce apoptosis in NCl-H460 cells and other NSCLC cell lines by a Caspase 8-dependent but death receptors and Caspase 9-independent pathway, with mitochondrial permeabilization and cytochrome $c$ release as primary events (Ferreira, Span et al. 2000). In our study, the cleavage of PARP and Caspases 3 , 8 and 9 confirmed apoptosis induction and suggested the activation of intrinsic and extrinsic pathways by both products but mainly by the combined treatment. Some authors have also showed that Cisplatinacquired resistance in other types of tumor like malignant pleural mesothelioma is associated with a reduction in Caspase 8 activation and therefore apoptosis induced by CDDP depends mainly on Caspase 9 activity (Janson, Johansson et al. 2010) Our results demonstrated a preferential cleavage of Caspase 9 in cells treated with the combination, particularly at 12 hours of incubation, thus the action of CIGB-552 could help to overcome or decrease Cisplatin resistance in treated cells. Finally, we corroborate apoptosis induction in $\mathrm{NCl}-\mathrm{H} 460$ cells by Annexin V/PI double staining, which revealed also a major percentage of apoptotic cells in response to the combined treatment in comparison to the individual drugs, confirming the synergic interaction between them.

Different authors have reported that the transcription factor NF-kB interferes with the mechanism of action of antineoplastic drugs by induction of antiapoptotic genes. Thus, the use of NF-kB inhibitors or new drugs that target this molecular factor as adjuvant treatments, could help to improve chemotherapy (Morotti, Cilloni et al. 2006, Lagadec, Griessinger et al. 2008, Achkar, Abdulrahman et al. 2018). NF-kB activation has been detected in many types of cancer including small and non-small cell lung cancer and high expression of this nuclear factor is correlated with progressive cancer and poor prognosis (Chen, $\mathrm{Li}$ et al. 2011). NF-kB is induced in cancer cells in response to chemotherapeutic agents like CDDP, as a tumor escape mechanism, related with chemoresistance and insensitivity to chemotherapy (Galluzzi, Senovilla et al. 2012, Godwin, Baird et al. 2013). Therefore, there are many studies that demonstrate a synergistic activity combining an NF-kB inhibitor with antineoplastic drugs. For example, Wang et al. 
demonstrated that Gambogic acid (GA), a strong NF-kB inhibitor, synergically potentiates CDDP-induced apoptosis in NCl-H460 cells (Wang, Li et al. 2014). Gambogic acid has antineoplastic and antiangiogenic properties and is currently in phase II of clinical trials for NSCLC treatment (Wang, Deng et al. 2013). Likewise, Bortezomib, a proteasomal inhibitor that decreases NF-kB activation, enhanced the sensitization of bladder and cervical cancers to CDDP (Miyamoto, Nakagawa et al. 2013, Konac, Varol et al. 2015). More recently, the natural bioflavonoid Galangin (GG), which inhibits NF-kB activity through downregulation of p-STAT3 signaling pathway, has demonstrated to inhibit proliferation and enhance the apoptosis induced by CDDP in human resistant lung cancer cells (Yu, Gong et al. 2018).

According to this, we corroborate synergism in antiproliferative effect and apoptosis induction between CIGB-552 and CDDP in NCl-H460 cells. The molecular mechanism of CIGB-552 is based on the inhibition of NF-kB signaling pathway mediated by the stabilization and accumulation of the intracellular protein COMMD1. (Fernández Massó, Oliva Argüelles et al. 2013). Thus, this could be a mechanism that plays an important role in the synergic effects between both drugs and could contribute to decrease cisplatin resistance in NSCLC. In addition, COMMD1 has demonstrated strong anticancer and antimetastatic effects in different cancer models (Van De Sluis, Mao et al. 2010, Riera-Romo 2018). Furthermore, Fedoseienko et al. demonstrated that nuclear expression of COMMD1 sensitizes tumor cells derived from advanced ovarian cancer patients to platinum-based therapy. They suggest that COMMD1 modulate the G2/M checkpoint, controlling expression of genes involved in DNA repair and apoptosis (Fedoseienko, Wieringa et al. 2016). Then, is reasonable to think that COMMD1 is also playing a key role in the molecular mechanism that mediates CIGB-552 synergism with CDDP in NCI-H460 cells.

On the other hand, tumor cells have increased levels of ROS due to their own metabolism deregulations, and it contributes to tumor development and drug resistance. In line with this, the pharmacological manipulation of the redox status to sensitize cancer cells to chemotherapeutic agents is another attractive strategy to increase efficacy and avoid MDR. (Dayem, Choi et al. 2010, Ma, Yang et al. 2014). In this work, we demonstrated that the combination of CIGB-552 and CDDP increases intracellular levels of ROS at short or prolonged exposure in $\mathrm{NCl}-\mathrm{H} 460$ cells and do not have effect on normal cells from the same localization, like MRC5 cells. These results suggest that selective induction of oxidative stress could be an additional mechanism by which CIGB-552/CDDP combination elicits its antitumor effects in NSCLC; an important advantage of the combination compared to CDDP monotherapy.

One of the mechanisms underlying CIGB-552 cytotoxicity in NCl-H460 cells is the COMMD1-mediated inhibition of SOD1 enzyme and the subsequent induction of oxidative stress (Fernández Massó, Oliva Argüelles et al. 2013). CDDP also cause an unspecific production of high ROS levels, which constitutes one of the main reasons of its toxicity (Chirino and Pedraza-Chaverri 2009). Therefore, the combination with CIGB-552 could contribute to reduce the nephrotoxicity and lymphopenia induced by CDDP in cancer patients.

Our results showed that CGB-552 induces oxidative stress as an early event, probably by COMMD1 stabilization and COMMD1-dependent SOD1 inhibition, whereas CDDP triggers ROS accumulation later in 
time, as a secondary event, derived from its sequential enzymatic biotransformation. This suggests that the peptide specifically sensitizes tumor cells to CDDP through the modulation of the redox state and consequently, both drugs combined generate sustained oxidative stress that reinforces apoptosis induction and achieves a higher antiproliferative effect (Fig. 6). Besides, both products are modulating the same cellular process but acting trough different pathways, which could also explain the synergic interaction between them. This idea has been supported by other authors, who point out oxidative stress modulation as an interesting strategy to eliminate cancer cells and sensitize them to chemotherapeutic treatments (Trachootham, Alexandre et al. 2009, Raj, Ide et al. 2011, Gorrini, Harris et al. 2013). For example, small molecules such as Resveratrol (trans-3, 4', 5-trihydroxystilbene) and Phenothiazines are able to sensitize human colon and lung cancer cells, respectively, to the action of different chemotherapeutic agents such as 5-Fluoracil (5-FU) to colon cancer and Bleomycin and CDDP to lung cancer, through the modulation of intracellular oxidative stress response (Santandreu, Valle et al. 2011, Zong, Hååg et al. 2011). Another example is the natural compound Shikonin, which triggering intracellular oxidative stress in colon cancer cells but not in normal cells, potentiated CDDP-induced DNA damage, followed by increased activation of the mitochondrial apoptotic pathway. The use of antioxidants and ROS scavengers revealed that ROS are essential to the synergism observed (He, He et al. 2016).

The results obtained in vitro were corroborated in vivo in a mouse model of TC-1 lung cancer, a recognized animal model for NSCLC (Tanaka, Delong et al. 2005). Co-administration of CIGB-552 and CDDP lead to a significant inhibition of tumor growth, with increased overall survival in treated animals and increasing the life of quality in comparison to control mice or mice treated with the drugs separately. In addition, the combination with CIGB-552 was able to significantly decreases the signs of physical deterioration associated with CDDP administration. This confirms that both drugs are acting synergically to achieve a better antitumor response and is correlated with the behaviour observed in in vitro studies. Similar results were obtained by Wang et al. with GA, which sensitizes human lung cancer cells to CDDP in vitro, by NF-kB inhibition and ROS intracellular accumulation, and was also effective in vivo, in a A549 xenograft mice model, where the combined administration with CDDP significantly decreased tumor volumes of treated animals, without body weight loss or associated toxicity (Wang, Li et al. 2014). In the same way, Shikonin that eliminates human colon cancer cells and sensitizes them to CDDP-induced apoptosis through the selective induction of oxidative stress, was also able to inhibit tumor growth in a HCT116 xenograft model in nude mice (He, He et al. 2016). More recently, Hsu et al. demonstrated the high potential of another natural compound, Withaferin A (WA) in lung cancer in vitro and in vivo. As occurred with CIGB-552, WA is selectively cytotoxic to different human lung cancer cells including various NSCLC cell lines, inducing apoptosis and increasing the intracellular accumulation of ROS as its antitumor mechanism. In addition, it decreases lung tumorigenesis in vivo in a NSCLC model of H441L2G bioluminescent cells implanted in nude mice. Similar to our results, WA and CDDP synergically inhibited NSCLC cell proliferation in a drug combination assay and WA enhanced CDDP cytotoxicity and antitumor activity in cell cultures and tumor spheroids (Hsu, Chang et al. 2019).

Taken together, all these findings demonstrate that targeting NF-kB activity and ROS response in tumor cells is an effective therapeutic strategy in NSCLC and other types of cancer, which can improve the 
response to different chemotherapeutic agents but particularly to CDDP, achieving synergistic effects and decreasing CDDP resistance. The combination of CIGB-552 and CDDP is able to modulate both molecular pathways, representing an important advantage in NSCLC treatment. Based on the presented evidence we propose a model in which CIGB-552 sensitizes lung cancer cells to CDDP through ROS accumulation and NF-kB inhibition, achieving synergism in apoptosis induction and reduction of tumor growth. This research is the first preclinical evidence about the combination of CIGB-552 and CDDP in the context of NSCLC and gives important findings that support the use of CIGB-552 as an adjuvant treatment in the clinics.

\section{Conclusions}

CIGB-552 is a new cancer targeted therapy that acts synergically with CDDP to inhibit proliferation and tumor growth of NSCLC in vitro and in vivo. The combination of CIGB-552 with chemotherapeutic agents like CDDP is an attractive strategy to selectively induce ROS and apoptosis in lung cancer cells, improving the antitumor efficacy of CDDP but decreasing its associated toxicity. This work also shows scientific evidence that could help in the rational design of a combined treatment for lung cancer based on CIGB552 , to be tested in clinical trials.

\section{Declarations}

\section{Funding:}

There is no funding source associated with this work

\section{Conflicts of interest/Competing interests:}

Authors do not declare any conflict of interests associated to this work.

\section{Availability of data and material:}

We declare total transparency with the data generated and presented in the above manuscript.

\section{Code availability:}

Not applicable.

\section{Authors' contributions:}


- Yolanda, Brizaida, Maribel, Julio, Cossio,Hilda: Substantial contributions to the conception or design of the work; or the acquisition, analysis, or interpretation of data for the work.

- Brizaida, Mario, Yolanda, Maribel: Drafting the work or revising it critically for important intellectual content

- Brizaida, Mario, Yolanda, Maribel: Final approval of the version to be published

- Yolanda, Brizaida, Maribel: Agreement to be accountable for all aspects of the work in ensuring that questions related to the accuracy or integrity of any part of the work are appropriately investigated and resolved.

\section{Ethics approval:}

All animal experiments were performed in accordance with the recommendations for the proper use and care of laboratory animals at the Center for Genetic Engineering and Biotechnology (Havana, Cuba) and were previously approved by this ethical committee. This animal study complies with all the international requirements and is according the National Institutes of Health guide for care and use of laboratory animals.

\section{Consent to participate:}

Non applicable.

\section{Consent for publication:}

Non applicable. We are using our own experiments and data.

\section{ACKNOWLEDGMENTS}

We would like to thank Freya Milagro Freyre Almeida, Yaima Chacon Quintero, Amalia Vazquez Arteaga, Tania Cardenas Borrego, Rocio Garateix Suarez, Enma Brown Richards, Dagmara Pichardo Diaz and Lizet Aldana Velazco for their advices and collaboration on this experimental work.

\section{References}

1. (2020). "Anuario Estadístico De Salud. Minsap, Cuba." Dirección Nacional De Registros Médicos Y Estadísticas De Salud, Havana, Cuba.

2. (2020). "Erratum: Global cancer statistics 2018: GLOBOCAN estimates of incidence and mortality worldwide for 36 cancers in 185 countries." CA Cancer J Clin70(4): 313. 
3. Achkar, I. W., N. Abdulrahman, H. Al-Sulaiti, J. M. Joseph, S. Uddin and F. Mraiche (2018). "Cisplatin based therapy: the role of the mitogen activated protein kinase signaling pathway." Journal of translational medicine16(1): 96.

4. Astrada, S., J. R. Fernández Massó, M. G. Vallespí and M. Bollati-Fogolín (2018). "Cell penetrating capacity and internalization mechanisms used by the synthetic peptide CIGB-552 and its relationship with tumor cell line sensitivity." Molecules23(4): 801.

5. Bayat Mokhtari, R., T. S. Homayouni, N. Baluch, E. Morgatskaya, S. Kumar, B. Das and H. Yeger (2017). "Combination therapy in combating cancer." Oncotarget8(23): 38022-38043.

6. Bordoni, R. (2008). "Consensus conference: multimodality management of early- and intermediatestage non-small cell lung cancer." Oncologist13(9): 945-953.

7. Boyd, M. R. (1997). The NCl in vitro anticancer drug discovery screen. Anticancer drug development guide, Springer: 23-42.

8. Bray, F., J. Ferlay, I. Soerjomataram, R. L. Siegel, L. A. Torre and A. Jemal (2018). "Global cancer statistics 2018: GLOBOCAN estimates of incidence and mortality worldwide for 36 cancers in 185 countries." CA Cancer J Clin68(6): 394-424.

9. Burnette, W. N. (1981). "? Western Blotting?: Electrophoretic transfer of proteins from sodium dodecyl sulfate-polyacrylamide gels to unmodified nitrocellulose and radiographic detection with antibody and radioiodinated protein A." Analytical biochemistry.112(2): 195-203.

10. Chen, W., Z. Li, L. Bai and Y. Lin (2011). "NF-kappaB in lung cancer, a carcinogenesis mediator and a prevention and therapy target." Front Biosci (Landmark Ed).16: 1172-1185.

11. Chirino, Y. I. and J. Pedraza-Chaverri (2009). "Role of oxidative and nitrosative stress in cisplatininduced nephrotoxicity." Experimental and Toxicologic Pathology61(3): 223-242.

12. Chou, T.-C. (2006). "Theoretical basis, experimental design, and computerized simulation of synergism and antagonism in drug combination studies." Pharmacological reviews58(3): 621-681.

13. Dayem, A. A., H.-Y. Choi, J.-H. Kim and S.-G. Cho (2010). "Role of oxidative stress in stem, cancer, and cancer stem cells." Cancers2(2): 859-884.

14. de Villavicencio-Díaz, T. N., Y. R. Gómez, B. O. Argüelles, J. R. F. Masso, A. Rodríguez-Ulloa, Y. C. García, O. Guirola-Cruz, Y. Perez-Riverol, L. J. González and I. J. J. o. p. Tiscornia (2015). "Comparative proteomics analysis of the antitumor effect of CIGB-552 peptide in HT-29 colon adenocarcinoma cells." 126: 163-171.

15. Fedoseienko, A., H. W. Wieringa, G. B. A. Wisman, E. Duiker, A. K. Reyners, M. H. Hofker, A. G. van der Zee, B. van de Sluis and M. A. van Vugt (2016). "Nuclear COMMD1 is associated with cisplatin sensitivity in ovarian cancer." PloS one11(10): e0165385.

16. Fernández Massó, J. R., B. Oliva Argüelles, Y. Tejeda, S. Astrada, H. Garay, O. Reyes, L. DelgadoRoche, M. Bollati-Fogolín and M. G. Vallespí (2013). "The antitumor peptide CIGB-552 increases COMMD1 and inhibits growth of human lung cancer cells." Journal of Amino Acids 2013.

17. Ferreira, C. G., S. W. Span, G. J. Peters, F. A. Kruyt and G. Giaccone (2000). "Chemotherapy triggers apoptosis in a caspase-8-dependent and mitochondria-controlled manner in the non-small cell lung 
cancer cell line NCl-H460." Cancer research60(24): 7133-7141.

18. Galluzzi, L., L. Senovilla, I. Vitale, J. Michels, I. Martins, O. Kepp, M. Castedo and G. Kroemer (2012). "Molecular mechanisms of cisplatin resistance." Oncogene31(15): 1869-1883.

19. Godwin, P., A.-M. Baird, S. Heavey, M. Barr, K. O'Byrne and K. A. Gately (2013). "Targeting nuclear factor-kappa B to overcome resistance to chemotherapy." Frontiers in oncology3: 120.

20. Gorrini, C., I. S. Harris and T. W. Mak (2013). "Modulation of oxidative stress as an anticancer strategy." Nature reviews Drug_discovery_12(12): 931-947.

21. Hanahan, D. and R. A. Weinberg (2011). "Hallmarks of cancer: the next generation." Cell144(5): 646674.

22. He, G., G. He, R. Zhou, Z. Pi, T. Zhu, L. Jiang and Y. Xie (2016). "Enhancement of cisplatin-induced colon cancer cells apoptosis by shikonin, a natural inducer of ROS in vitro and in vivo." Biochemical and biophysical research communications469(4): 1075-1082.

23. Hsu, J. H.-M., P. M.-H. Chang, T.-S. Cheng, Y.-L. Kuo, A. T.-H. Wu, T.-H. Tran, Y.-H. Yang, J.-M. Chen, Y.-C. Tsai and Y.-S. Chu (2019). "Identification of withaferin A as a potential candidate for anti-cancer therapy in non-small cell lung cancer." Cancers11(7): 1003.

24. Janson, V., A. Johansson and K. Grankvist (2010). "Resistance to caspase-8 and-9 fragments in a malignant pleural mesothelioma cell line with acquired cisplatin-resistance." Cell death \& disease1(9): e78-e78.

25. Konac, E., N. Varol, I. Kiliccioglu and C. Y. Bilen (2015). "Synergistic effects of cisplatin and proteasome inhibitor bortezomib on human bladder cancer cells." Oncology letters 10(1): 560-564.

26. Lagadec, P., E. Griessinger, M. Nawrot, N. Fenouille, P. Colosetti, V. Imbert, M. Mari, P. Hofman, D. Czerucka and D. Rousseau (2008). "Pharmacological targeting of NF-KB potentiates the effect of the topoisomerase inhibitor CPT-11 on colon cancer cells." British journal of cancer98(2): 335-344.

27. Li, F., C. Zhao and L. Wang (2014). "Molecular-targeted agents combination therapy for cancer: developments and potentials." Int J Cancer134(6): 1257-1269.

28. Ma, J., J. Yang, C. Wang, N. Zhang, Y. Dong, C. Wang, Y. Wang and X. Lin (2014). "Emodin augments cisplatin cytotoxicity in platinum-resistant ovarian cancer cells via ROS-dependent MRP1 downregulation." BioMed research international2014.

29. Meng, G., W. Wang, K. Chai, S. Yang, F. Li and K. Jiang (2015). "Combination treatment with triptolide and hydroxycamptothecin synergistically enhances apoptosis in A549 lung adenocarcinoma cells through PP2A-regulated ERK, p38 MAPKs and Akt signaling pathways." International journal of oncology_46(3): 1007-1017.

30. Miyamoto, Y., S. Nakagawa, O. Wada-Hiraike, T. Seiki, M. Tanikawa, H. Hiraike, K. Sone, K. Nagasaka, K. Oda and K. Kawana (2013). "Sequential effects of the proteasome inhibitor bortezomib and chemotherapeutic agents in uterine cervical cancer cell lines." Oncology_reports 29(1): 51-57.

31. Morotti, A., D. Cilloni, M. Pautasso, F. Messa, F. Arruga, I. Defilippi, S. Carturan, R. Catalano, V. Rosso and A. Chiarenza (2006). "NF-kB inhibition as a strategy to enhance etoposide-induced apoptosis in K562 cell line." American journal of hematology_81(12): 938-945. 
32. Raj, L., T. Ide, A. U. Gurkar, M. Foley, M. Schenone, X. Li, N. J. Tolliday, T. R. Golub, S. A. Carr and A. F. Shamji (2011). "Selective killing of cancer cells by a small molecule targeting the stress response to ROS." Nature475(7355): 231-234.

33. Riera-Romo, M. (2018). "COMMD1: a multifunctional regulatory protein." Journal of Cellular Biochemistry_119(1): 34-51.

34. Santandreu, F. M., A. Valle, J. Oliver and P. Roca (2011). "Resveratrol potentiates the cytotoxic oxidative stress induced by chemotherapy in human colon cancer cells." Cellular Physiology and Biochemistry.28(2): 219-228.

35. Tallarida, R. J. (2001). "Drug synergism: its detection and applications." J Pharmacol Exp Ther298(3): 865-872.

36. Tanaka, T., P. A. Delong, K. Amin, A. Henry, R. Kruklitis, V. Kapoor, L. R. Kaiser and S. M. Albelda (2005). "Treatment of lung cancer using clinically relevant oral doses of the cyclooxygenase-2 inhibitor rofecoxib: potential value as adjuvant therapy after surgery." Annals of surgery_241(1): 168.

37. Thoms, H. C., C. J. Loveridge, J. Simpson, A. Clipson, K. Reinhardt, M. G. Dunlop and L. A. Stark (2010). "Nucleolar targeting of RelA (p65) is regulated by COMMD1-dependent ubiquitination." Cancer research70(1): 139-149.

38. Tiwari, A. K., K. Sodani, C. L. Dai, C. R. Ashby, Jr. and Z. S. Chen (2011). "Revisiting the ABCs of multidrug resistance in cancer chemotherapy." Curr Pharm Biotechnol12(4): 570-594.

39. Trachootham, D., J. Alexandre and P. Huang (2009). "Targeting cancer cells by ROS-mediated mechanisms: a radical therapeutic approach?" Nature reviews Drug discovery_8(7): 579-591.

40. Vallespí, M. G., G. Pimentel, A. Cabrales-Rico, J. Garza, B. Oliva, O. Mendoza, Y. Gomez, T. Basaco, I. Sánchez and C. Calderón (2014). "Antitumor efficacy, pharmacokinetic and biodistribution studies of the anticancer peptide CIGB-552 in mouse models." Journal of peptide science20(11): 850-859.

41. Vallespi, M. G., J. C. Rodriguez, L. C. Seoane, P. Alvarez, H. Santana, H. Garay, I. A. Cabrera, J. T. Espinosa and O. Reyes (2017). "The first report of cases of pet dogs with naturally occurring cancer treated with the antitumor peptide CIGB-552." Research in veterinary science 114: 502-510.

42. Van De Sluis, B., X. Mao, Y. Zhai, A. J. Groot, J. F. Vermeulen, E. Van Der Wall, P. J. Van Diest, M. H. Hofker, C. Wijmenga and L. W. Klomp (2010). "COMMD1 disrupts HIF-1a/ $\beta$ dimerization and inhibits human tumor cell invasion." The Journal of clinical investigation120(6): 2119-2130.

43. Wagner, G., H. K. Stollenwerk, I. Klerings, M. Pecherstorfer, G. Gartlehner and J. Singer (2020). "Efficacy and safety of immune checkpoint inhibitors in patients with advanced non-small cell lung cancer (NSCLC): a systematic literature review." Oncoimmunology_9(1): 1774314.

44. Walrand, S., S. Valeix, C. Rodriguez, P. Ligot, J. Chassagne and M.-P. Vasson (2003). "Flow cytometry study of polymorphonuclear neutrophil oxidative burst: a comparison of three fluorescent probes." Clinica chimica acta331(1-2): 103-110.

45. Wang, L., Y. Li, S. Yang, F. Wang, Y. Hou, W. Cui, K. Chen, Q. Cao, S. Wang and T. Zhang (2014). "Gambogic acid synergistically potentiates cisplatin-induced apoptosis in non-small-cell lung cancer through suppressing NF-KB and MAPK/HO-1 signalling." British journal of cancer110(2): 341-352. 
46. Wang, X., R. Deng, Y. Lu, Q. Xu, M. Yan, D. Ye and W. Chen (2013). "Gambogic Acid as a NonCompetitive Inhibitor of ATP-Binding Cassette Transporter B1 Reverses the Multidrug Resistance of Human Epithelial Cancers by Promoting ATP-Binding Cassette Transporter B1 Protein Degradation." Basic \& clinical pharmacology \& toxicology 112(1): 25-33.

47. Wojtala, A., M. Bonora, D. Malinska, P. Pinton, J. Duszynski and M. R. Wieckowski (2014). Methods to monitor ROS production by fluorescence microscopy and fluorometry. Methods in enzymology, Elsevier. 542: 243-262.

48. Yu, S., L.-s. Gong, N.-f. Li, Y.-f. Pan and L. Zhang (2018). "Galangin (GG) combined with cisplatin (DDP) to suppress human lung cancer by inhibition of STAT3-regulated NF-KB and Bcl-2/Bax signaling pathways." Biomedicine \& Pharmacotherapy 97 : 213-224.

49. Zong, D., P. Hååg, I. Yakymovych, R. Lewensohn and K. Viktorsson (2011). "Chemosensitization by phenothiazines in human lung cancer cells: impaired resolution of $\mathrm{Y} H 2 \mathrm{AX}$ and increased oxidative stress elicit apoptosis associated with lysosomal expansion and intense vacuolation." Cell death \& disease2(7): e181-e181.

\section{Figures}

A

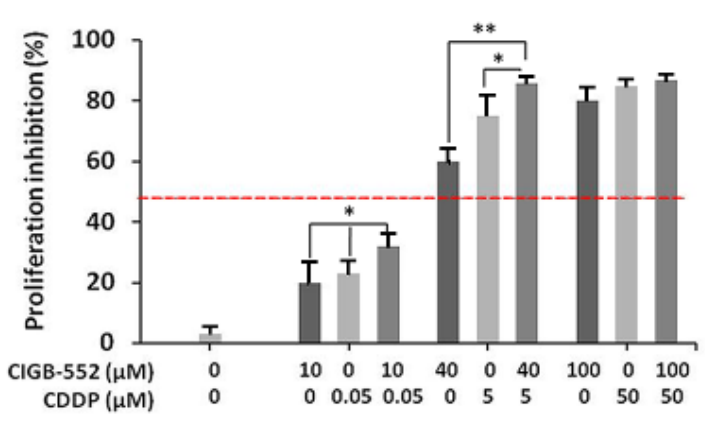

B

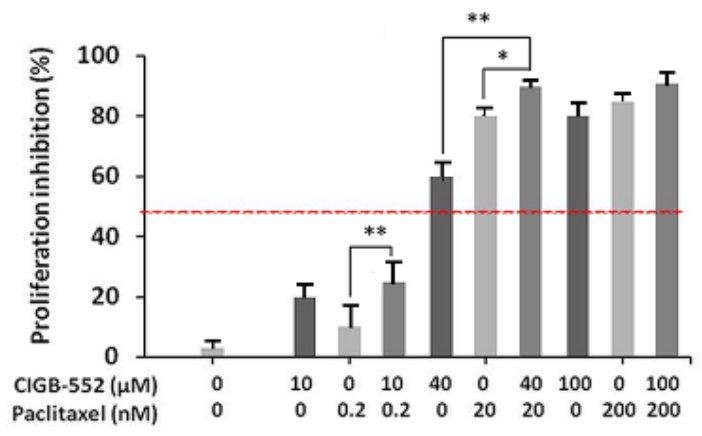

C
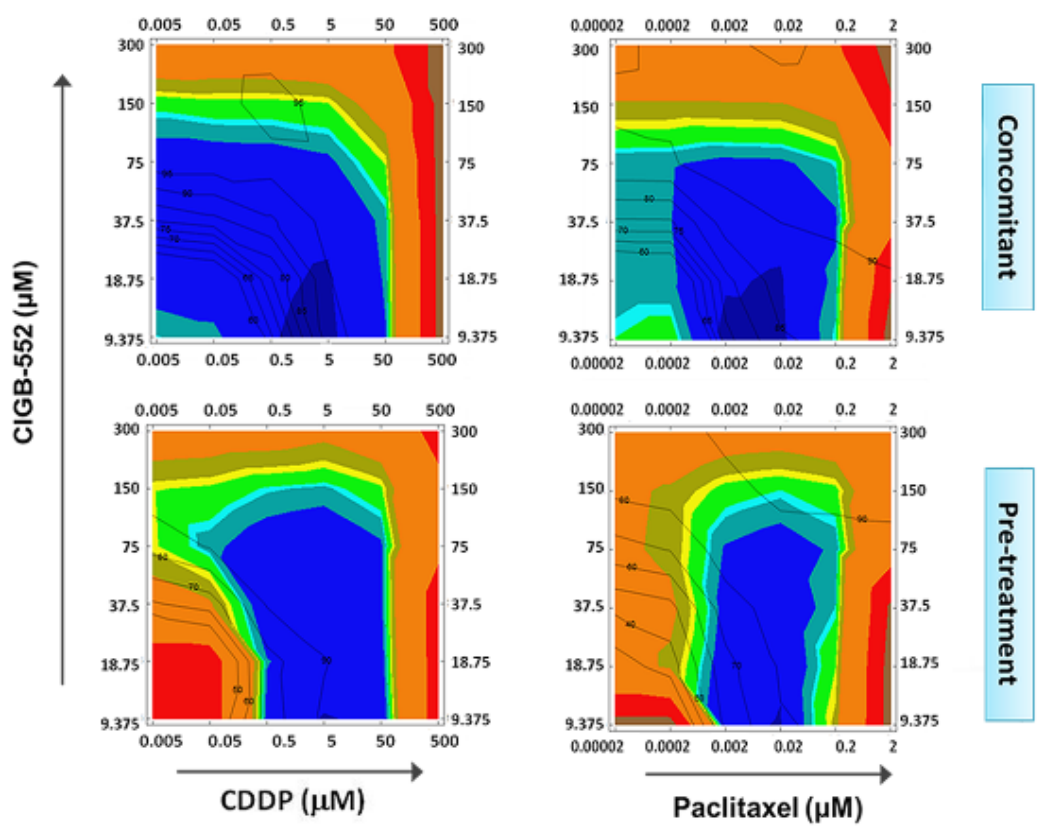

$\begin{array}{llllll}0.00002 & 0.0002 & 0.002 & 0.02 & 0.2 & 2\end{array}$
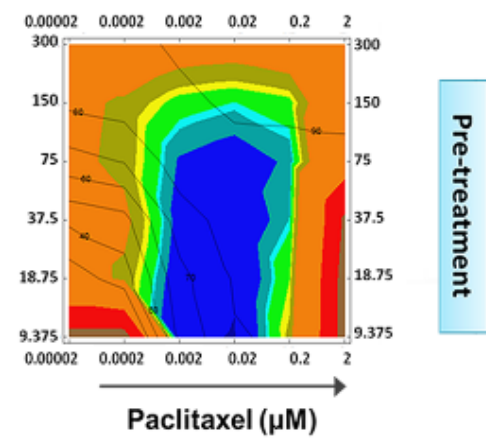

Figure 1

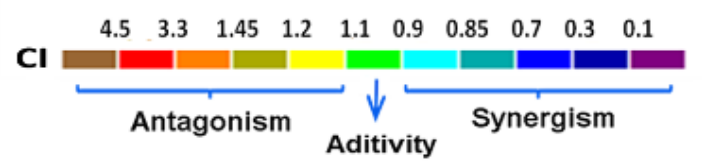


Antiproliferative effects of CIGB-552, CDDP and Paclitaxel in NCl-H460 cells. A) Proliferation inhibition induced by CIGB-552 and CDDP (A) or Paclitaxel (B) alone and combined at selected concentrations in $\mu \mathrm{M}$. C) Color surface interaction map, based on $\mathrm{Cl}$ values from in vitro drug combination assay for CIGB552 with CDDP and Paclitaxel under concomitant and pre-treatment settings. * $p<0.05,{ }^{\star *} p<0.01$ for the combination in comparison to individual treatments (One way ANOVA and Dunnet post test).
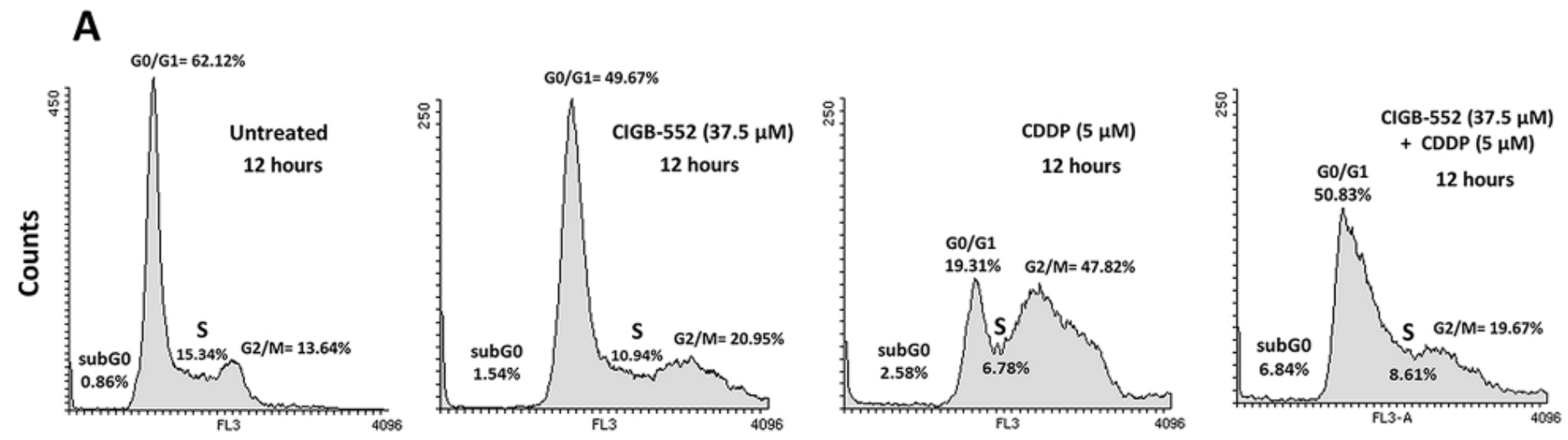

B
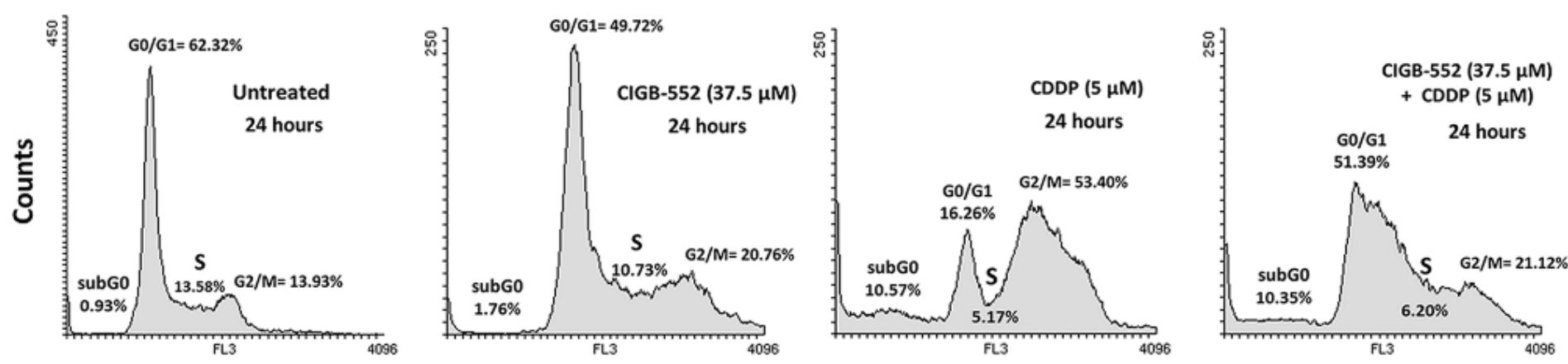

Figure 2

Cell cycle profile of NCl-H460 cells treated with CIGB-552 $(37.5 \mu \mathrm{M}), \operatorname{CDDP}(5 \mu \mathrm{M})$ and the combination of both drugs for 12 (A) and 24 hours (B). The DNA content was assessed by Propidium lodide (PI) staining and flow cytometry. The percentage of cells in each cell cycle phase is represented in the corresponding histograms. 
A

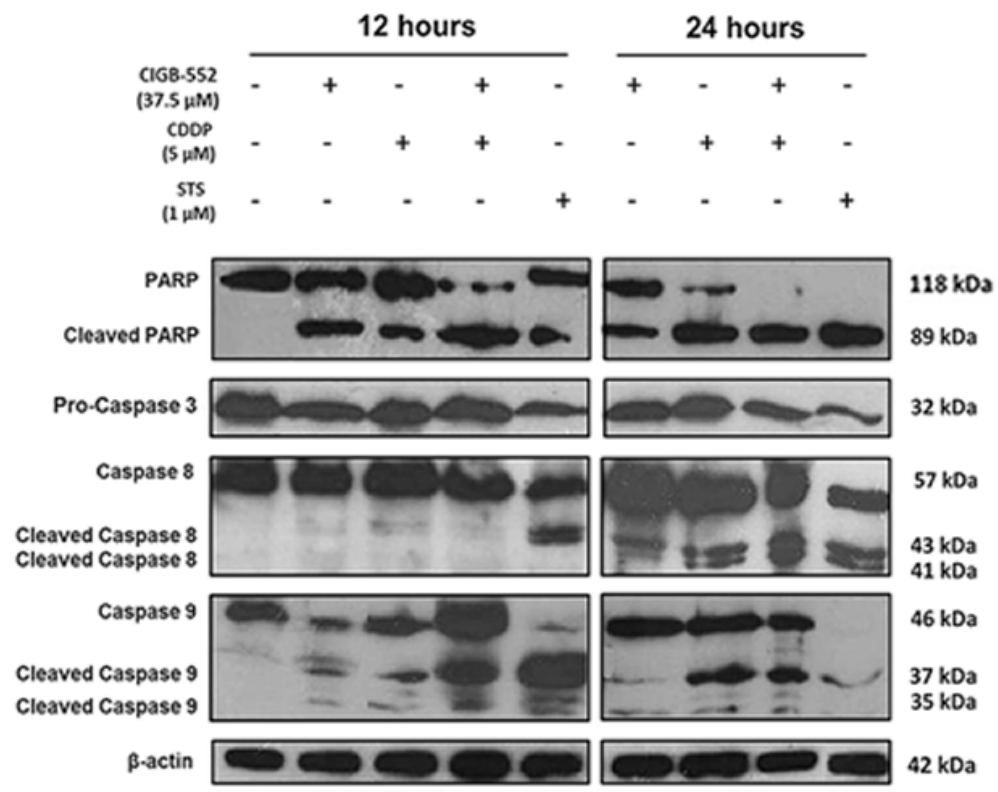

C

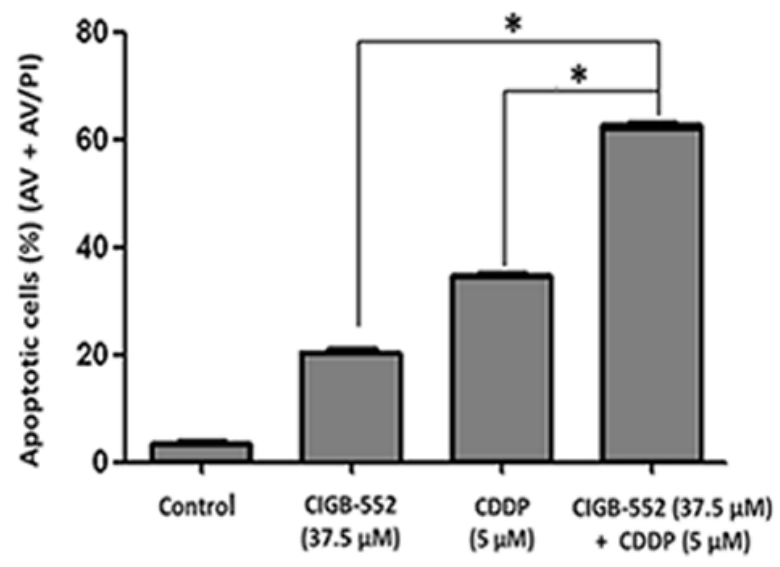

\section{B}
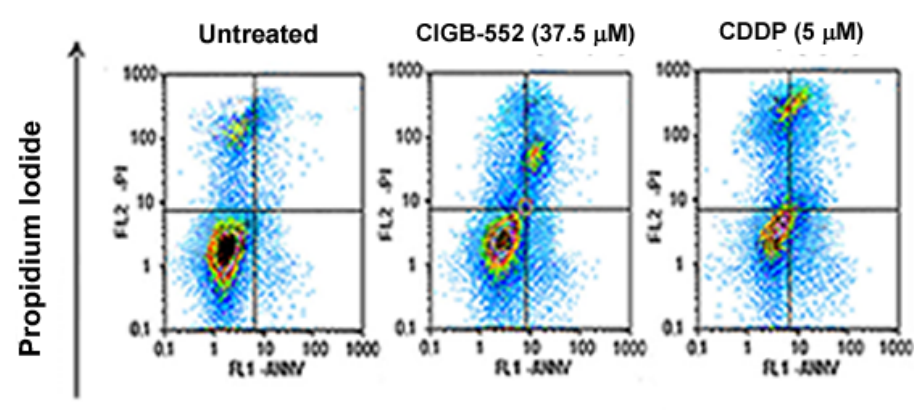

CIGB-552 (37.5 $\mu \mathrm{M})$

$+\operatorname{CDDP}(5 \mu \mathrm{M})$
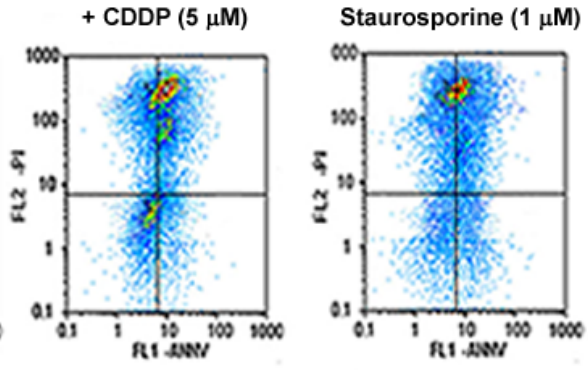

Annexin V-FITC

\section{Figure 3}

Apoptosis induction in NCl-H460 cells mediated by CIGB-552 (37.5 $\mu \mathrm{M})$ and CDDP( $5 \mu \mathrm{M})$ alone and combined. A) Western Blott of apoptosis-related proteins in response to 12 and 24 hours of exposure to the products. Staurosporin (STS) $1 \mu \mathrm{M}$, was used as positive control. B) Cell distribution on the Annexin V/Propidium lodide (AV/PI) double staining assessed by flow cytometry after 48 of exposure to the drugs. STS $(1 \mu \mathrm{M})$ was also included as positive control for the experiment. C) Percentage of apoptotic cells (AV $+\mathrm{AV} / \mathrm{PI}$ ) from the double staining assay in response to each treatment. * $p<0.05$, for the combination in comparison to individual treatments (One way ANOVA and Dunnet post test). 
A

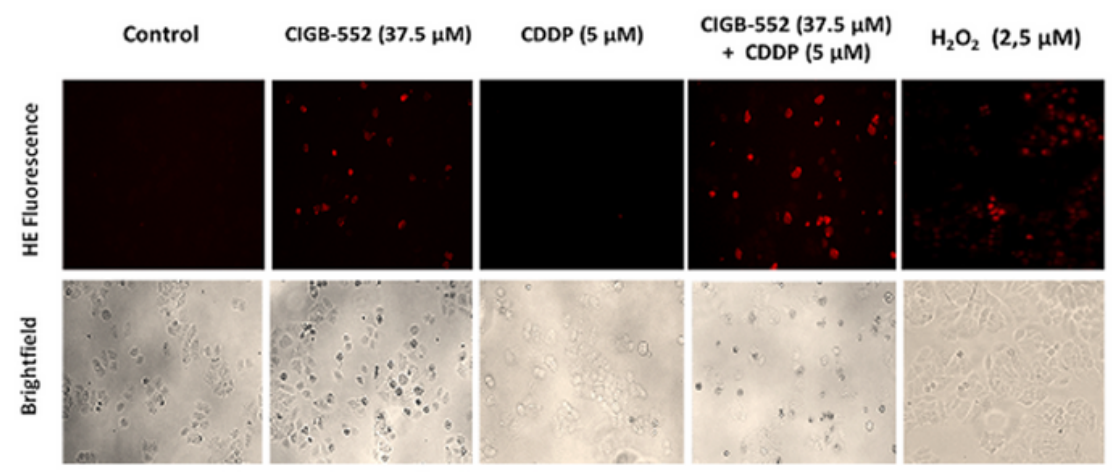

B

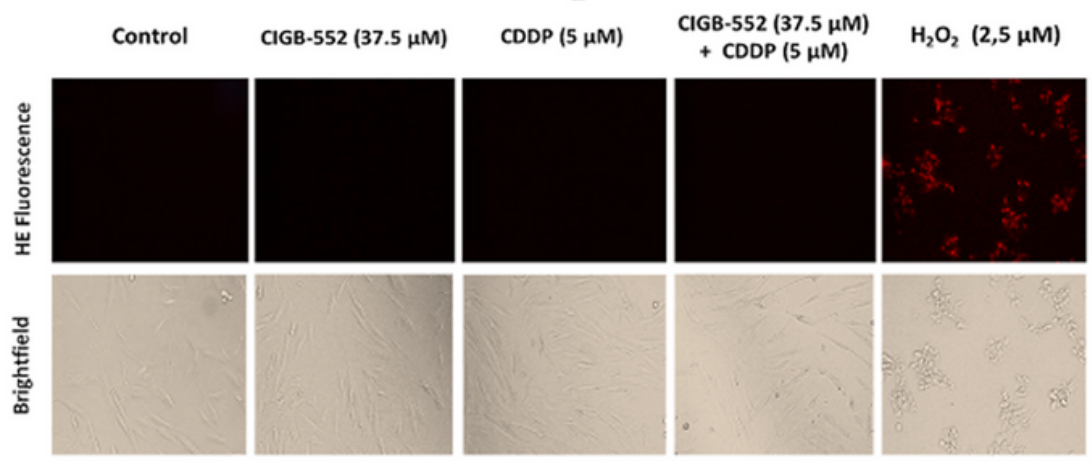

C
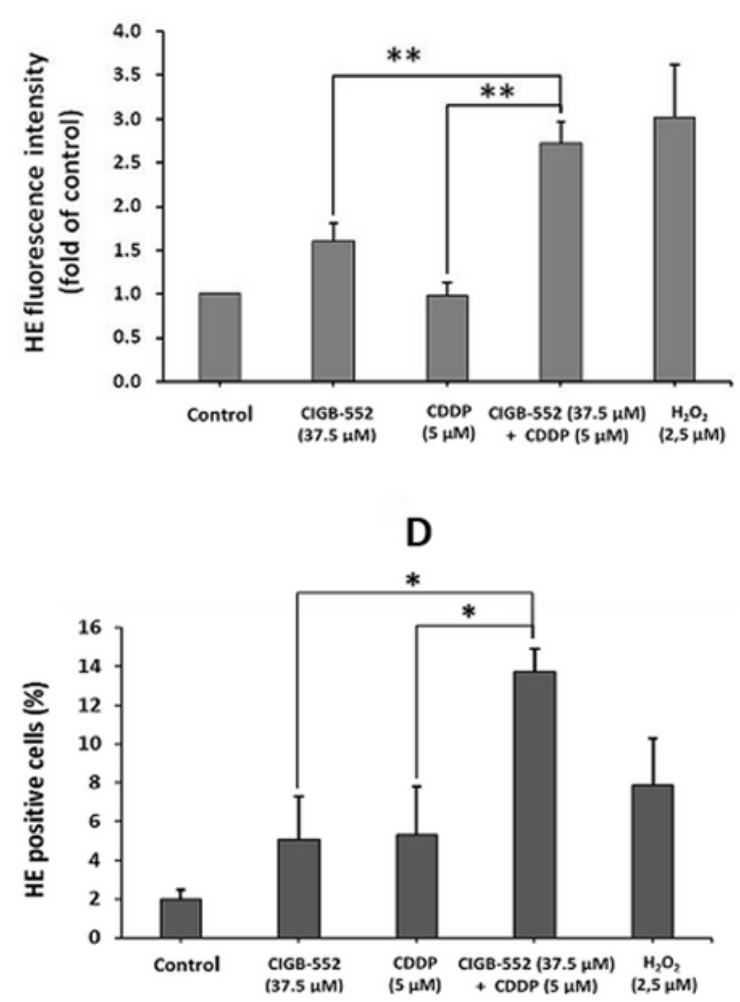

\section{Figure 4}

Superoxide anion (02--) accumulation assays in response to CIGB-552 $(37.5 \mu \mathrm{M})$ and $\operatorname{CDDP}(5 \mu \mathrm{M})$ alone and in combination. A) Fluorescence microscopy images from Hydroethidine (HE) staining in $\mathrm{NCl}-\mathrm{H} 460$ (A) and MRC-5 cells (B) to detect $02 \cdot-$ accumulation in response to 1 hour exposure to the products. $C$ ) $\mathrm{HE}$ fluorescence intensity as fold of control in $\mathrm{NCl}-\mathrm{H} 460$ cells in response to the treatments, quantified from microscopy images with Image 1.41 software. ** $p<0.01$ for the combination in comparison to individual treatments (One way ANOVA and Dunnet post test). D) HE positive cells in percent, after 12 hours of exposure to the products in $\mathrm{NCl}-\mathrm{H} 460$ cell line, assessed by flow cytometry. ${ }^{*} p<0.05$ for the combination in comparison to individual treatments (Unpaired T test). $\mathrm{H} 2 \mathrm{O} 2(2.5 \mathrm{mM})$ was included as a positive control for all experiments. 

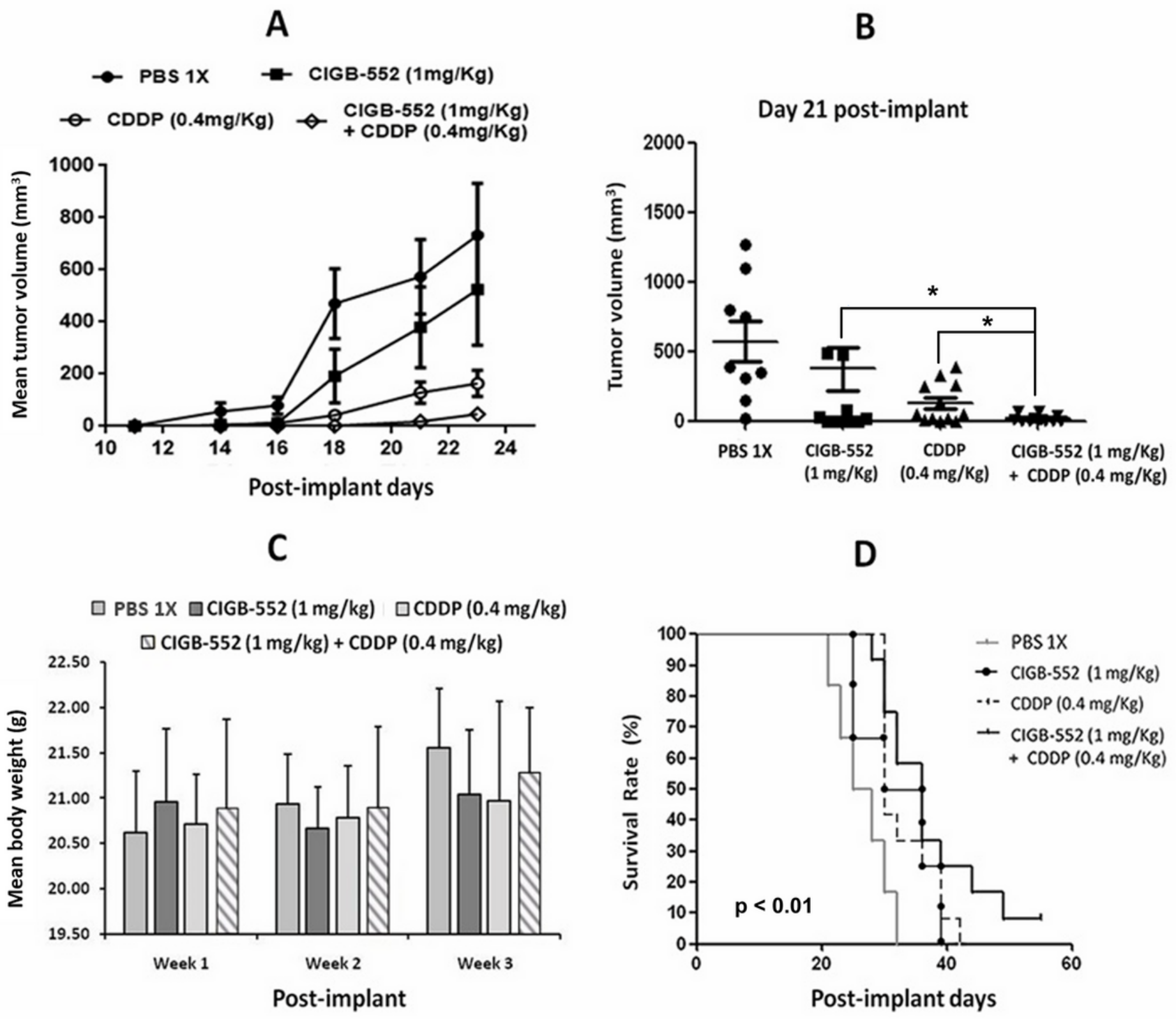

Figure 5

In vivo antitumor activity of CIGB-552 (1 mg/ $\mathrm{kg}$ s.c.) and CDDP (0.4 mg/kg i.p.) in a TC-1 lung cancer model in C57/BL6 mice. A) Mean tumor volume of treated and control mice from 10 to 24 days postimplantation of TC-1 cells. B) Tumor volume of animals from the four experimental groups at day 21 post-implant. Control animals only received saline solution (PBS $1 X$ s.c.) * $p<0.05$ for the combination in comparison to individual treatments (Unpaired T test). C) Mean body weight of treated and control mice measured once a week during the three weeks of the experiment. D) Kaplan-Meier survival curves of control and treated animals from implantation to 60 days post-implant. Log-rank analysis showed statistical differences between treated and control animals $(p<0.01)$. 


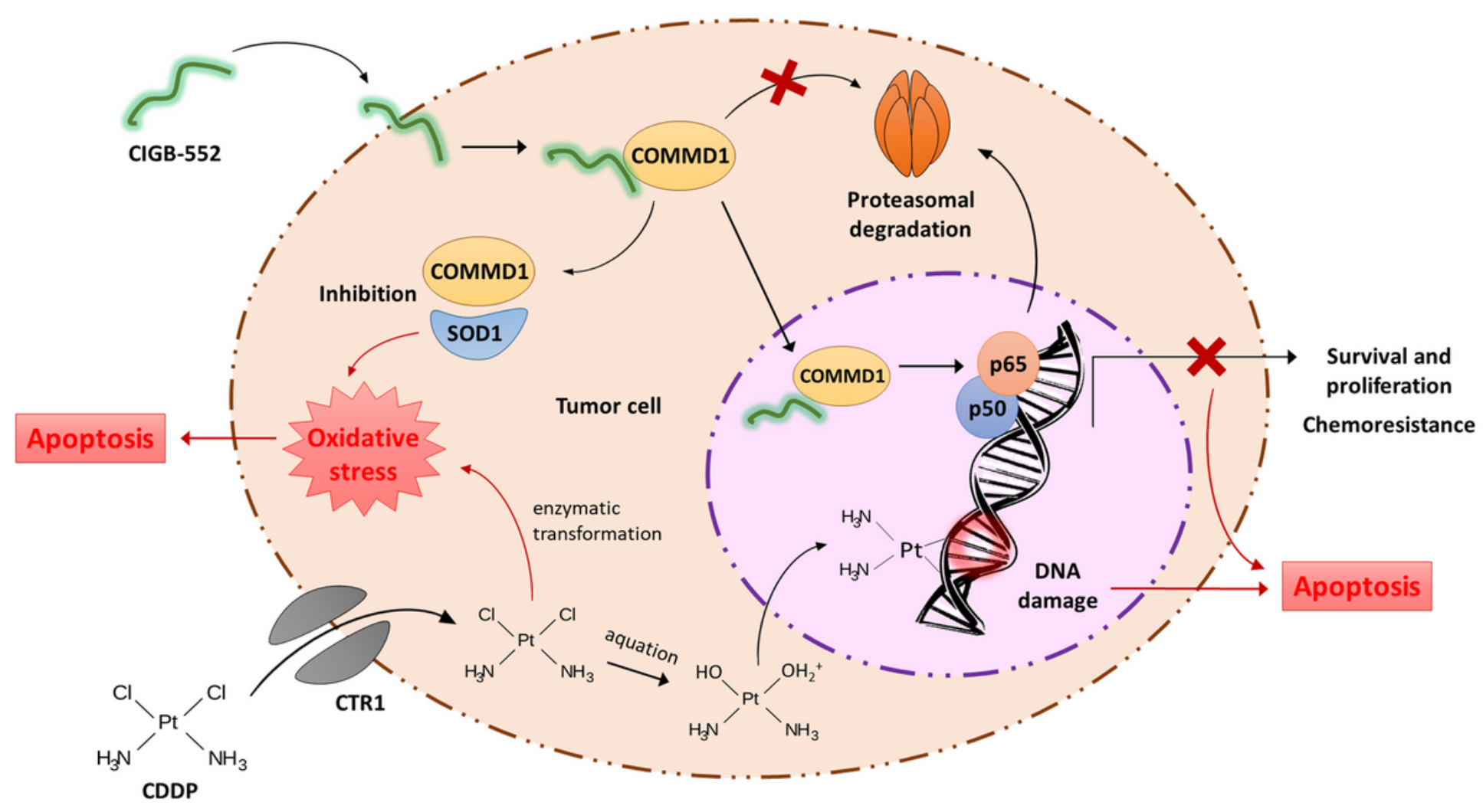

Figure 6

Hypothetical mechanism proposed to explain the synergic effects between CIGB-552 and CDDP in lung cancer cells. Both drugs target oxidative stress and apoptosis in tumor cells but acting through different pathways. CDDP intercalates in the DNA inducing DNA damage and cell death by apoptosis and at the same time, it causes a progressive reactive oxygen species (ROS) accumulation and oxidative stress as a result of its enzymatic biotransformation. On the other hand, CIGB-552 stabilizes and accumulates COMMD1 leading to the downregulation of the NF-kB signaling and consequently it inhibits the transcription of antiapoptotic and pro-survival genes. This effect enhances the CDDP-induced apoptosis and decreases chemoresistance. In addition, the COMMD1-mediated inhibition of SOD1 enzyme induced by CIGB-552 also triggers oxidative stress. The sustained and synergic oxidative stress activation by both products eventually leads to apoptotic cell death as well. CDDP: Cisplatin, CTR1: High affinity copper uptake protein 1; CIGB-552: anticancer cell penetrating peptide; COMMD1: Copper Metabolism Murr 1 Domain Containing Protein 1; SOD1: Superoxide Dismutase 1; p50/p65: NF-kB subunits. Black arrows indicate individual effects and red arrows indicate synergic effects. Red crosses indicate inhibition.

\section{Supplementary Files}

This is a list of supplementary files associated with this preprint. Click to download.

- SupplementTC1cells.docx

- FigureS1.tif 